\title{
PV-Battery Community Energy Systems: Economic, Energy Independence and Network Deferral Analysis
}

DOI:

10.1109/EEM.2017.7982021

\section{Document Version}

Accepted author manuscript

Link to publication record in Manchester Research Explorer

\section{Citation for published version (APA):}

Wang, H., Good, N., Mancarella, P., \& Lintern, K. (2017). PV-Battery Community Energy Systems: Economic, Energy Independence and Network Deferral Analysis. In European Energy Market (EEM), 2017 14th International Conference on the https://doi.org/10.1109/EEM.2017.7982021

\section{Published in:}

European Energy Market (EEM), 2017 14th International Conference on the

\section{Citing this paper}

Please note that where the full-text provided on Manchester Research Explorer is the Author Accepted Manuscript or Proof version this may differ from the final Published version. If citing, it is advised that you check and use the publisher's definitive version.

\section{General rights}

Copyright and moral rights for the publications made accessible in the Research Explorer are retained by the authors and/or other copyright owners and it is a condition of accessing publications that users recognise and abide by the legal requirements associated with these rights.

\section{Takedown policy}

If you believe that this document breaches copyright please refer to the University of Manchester's Takedown Procedures [http://man.ac.uk/04Y6Bo] or contact uml.scholarlycommunications@manchester.ac.uk providing relevant details, so we can investigate your claim.

\section{OPEN ACCESS}




\title{
PV-Battery Community Energy Systems: Economic, Energy Independence and Network Deferral Analysis
}

\author{
Han Wang ${ }^{1}$, Nicholas Good ${ }^{2}$, Pierluigi Mancarella ${ }^{1,2}$ and Kerry Lintern ${ }^{3}$ \\ ${ }^{1}$ Department of Electrical and Electronic Engineering, The University of Melbourne, Melbourne, Australia \\ ${ }^{2}$ School of Electrical and Electronic Engineering, The University of Manchester, Manchester, UK \\ ${ }^{3}$ AusNet Services, Melbourne, Australia
}

wangh12@student.unimelb.edu.au; \{nicholas.good,p.mancarella\}@manchester.ac.uk; pierluigi.mancarella@unimelb.edu.au; kerry.lintern@ausnetservices.com.au

\begin{abstract}
This paper presents a mixed integer linear program based model to optimize smart community energy systems, based upon physical models of buildings, energy storage, and energy conversion devices. Using a level-of-aggregation approach, the model can accommodate different price components at the relevant aggregation level. Community energy systems with various characteristics have been assessed considering different objectives (i.e., energy minimization, cost minimization and electricity self-sufficiency). Community behavior and economic performance are assessed to demonstrate the impact of different operation objectives and energy storage options on network constraints and economics.
\end{abstract}

Index Terms-Smart communities; community energy systems; optimization; price signal; battery energy storage.

\section{NOTATION}

A. Indices

$i \quad$ Index of settlement period, 1 to $N_{i}$

$l \quad$ Index of locations, 1 to $N_{l}$

$g \quad$ Index of Grid Connection Points (GCP), 1 to $N_{g}$

$v \quad$ Index of Virtual Power Plant (VPP), 1 to $N_{v}$

B. Maps

$\phi_{g, l}^{G L} / \phi_{v, g}^{V G} \quad$ Map of GCP to location/VPP to GCP

C. Parameters

1) Resources

$P_{l}^{E B \min } / P_{l}^{E B \max }$

$P_{l}^{H V A C m i n} / P_{l}^{H V A C m a x}$

$P_{l}^{B E S \sin } / P_{l}^{B E S \max }$

$B_{l}^{\min } / B_{l}^{\max }$

$E_{i, l}^{\text {solar }}$

Int $_{i, l} /$ Sol $_{i, l}$

$T_{i, l}^{\text {set }}$

$\rho_{i, l}^{E B} / \rho_{i, l}^{H V A C}$

$\varphi_{l}$

$\delta$

$R_{l}^{b}$
Electric boiler min/max power $(\mathrm{kW})$

HVAC min/max power $(\mathrm{kW})$

Battery min/max charge rate $(\mathrm{kW})$

Battery min/max capacity $(\mathrm{kWh})$

Solar electrical energy ( $\mathrm{kWh})$

Metabolic/solar heat gains $(\mathrm{kWh})$

Building set temperature $\left({ }^{\circ} \mathrm{C}\right)$

Electric boiler efficiency/HVAC COP

Battery round-trip efficiency

Blind exclusion efficiency

Building thermal resistance $\left({ }^{\circ} \mathrm{C} / \mathrm{kW}\right)$
$C_{l}^{b} \quad$ Building thermal capacitance $\left(\mathrm{kWh} /{ }^{\circ} \mathrm{C}\right)$

$M \quad$ Arbitrarily large number

2) Consumer energy/occupancy and temperature profiles

$O_{i, l} \quad$ Indicator of active occupancy

$H_{i, l}^{D H W} \quad$ Hot water demand (kWh)

$E_{i, l}^{\text {load }} \quad$ Non-heating electricity load (kWh)

$T_{i}^{\text {out }} \quad$ Outside temperature $\left({ }^{\circ} \mathrm{C}\right)$

3) Prices

$\lambda_{i} \quad$ Wholesale electricity price $(\$ / \mathrm{kWh})$

$\lambda_{i, g}^{-} / \lambda_{i, l}^{-} \quad \mathrm{GCP} /$ location electricity import price $(\$ / \mathrm{kWh})$

4) Time-band length

$t$

Length of time step (h)

D. Variables

$H_{i, l}^{E B} \quad$ Electric boiler heating $(\mathrm{kWh})$

$H_{i, l}^{H V A C} / C_{i, l}^{H V A C} \quad$ HVAC heating/cooling $(\mathrm{kWh})$

$P_{i, l}^{B E S+} / P_{i, l}^{B E S-} \quad$ Battery export/import power $(\mathrm{kW})$

$B_{l}^{\text {min }} / B_{l}^{\text {max }} \quad$ Battery min/max capacity $(\mathrm{kWh})$

$B_{i, l} \quad$ Battery energy level (kWh)

$E_{i, l}^{-} / E_{i, l}^{+}$

$E_{i, g}^{-} / E_{i, g}^{+}$

$E_{i, v}$

Location electricity import/export (kWh)

$T_{i, l}$

$v_{i, l} / w_{i, l}$

GCP electricity import/export (kWh)

VPP electricity (kWh)

$y_{i, l} / z_{i, g}$

Building temperature $\left({ }^{\circ} \mathrm{C}\right)$

$\pi_{i, l} / \beta_{i, l}$

$S / W$

Binary $\mathrm{HVAC} / \mathrm{BES}$ function indicator

Binary location/GCP import/export indicator

Degree of ventilation of $\operatorname{Int}_{i, l} /$ Sol $_{i, l}$

Binary summer/winter indicator

\section{INTRODUCTION}

Dramatic solar photovoltaic (PV) uptake has been experienced due to the substantial PV panel price drop [1] and the increase of the grid electricity prices in recent years. As a distributed renewable energy source (RES), home PV units have numerous advantages in terms of reducing greenhouse emissions, improving energy efficiency by reducing transmission and distribution network losses, and providing economic benefit to consumers. However, associated problems for network operators are likely to increase [2], [3]. In 
particular, the tendency of distributed PV to cluster geographically [4] will result in capacity problems, i.e., the local network struggling to accommodate export of surplus electricity from PV generation. Additionally, high penetration of PV might also increase network voltage and thermal problems [2]. On the other hand, the spread of distributed PV is also motivating interests from consumers and communities who wish to become "independent" of the grid [5], i.e., minimizing, ideally eliminating, the import and export of electricity from the grid to achieve self-sufficiency, especially in those rural areas where the grid operation, maintenance, and expansion are particularly expensive. However, that might increase the network charge per energy unit to the remaining customers, which is the grid costs distributed over connected customers [5], or may motivate the levying of generation network charges on distributed generation (such as PV) to pay for network enhancements necessary to deal with significant reverse flows.

Energy storage, of electricity or some derivative product such as hot water or building thermal inertia [6], provides an opportunity to deal with network problems without expensive reinforcement [7], [8]. Although battery energy storage (BES) could play an essential role in integrating home PV by providing flexibility to avoid expensive network reinforcement (possibly generating revenue for the battery owner), its high investment costs have prevented it from being commonly used. Various studies of integrating PV using BES commonly express confusion on the degree to which various objectives (e.g., electricity self-sufficiency, energy minimization, and cost minimization) are equivalent. In particular the opportunity afforded by exposure to wholesale-level prices is often neglected.

Addressing the issues described above, and drawing on previous work [6], [9], this paper presents a community energy optimization model, considering space heating/cooling, domestic hot water (DHW), non-heating electricity demand, PV generation, and BES. Various case studies (for different types of buildings/communities) are presented to demonstrate how the model can be used to assess the capability of communities with BES to ameliorate capacity constraints under different objectives. The business case for each case will be assessed via a Cost Benefit Analysis (CBA). Subsequently, the effect of different price signals (e.g., wholesale electricity price and Use-of-System (UoS) fees) on communities' operation and economic performance are assessed. The comparative economic performance of different objectives will reveal the cost of true energy independence for the consumer, as well as the cost of storage and demand response as a substitution for network reinforcement for the network operator.

\section{MODEL FORMULATION}

This study employs a mixed integer linear programming (MILP) approach to model communities where buildings use heating, ventilation and air-condition (HVAC) units for the provision of space heating and cooling, and electric boiler (EB) for DHW. The presented formulation allows the modelling of HVAC, EB, PV and BES at location level. In order to charge different electricity price components at the relevant level, energy demand and consumption profiles of each location are aggregated to a grid connection point (GCP) and virtual power plant (VPP) [6], [9], [10]. The following sections detail the energy resources modelling and different objective functions.

\section{A. Resources modelling}

1) Heating and cooling unit operating limits

Constraints (1) and (2) illustrate the operation limits of EB and HVAC at each location respectively. Constraint (3) ensures that HVAC units do not provide heating and cooling at the same time. EB heating is set to meet DHW demand by using (4).

$$
\begin{gathered}
P_{l}^{E B m i n} \rho_{i, l}^{E B} t \leq H_{i, l}^{E B} \leq P_{l}^{E B m a x} \rho_{i, l}^{E B} t \\
P_{l}^{H V A C \min } \leq\left(H_{i, l}^{H V A C}+C_{i, l}^{H V A C}\right) / \rho_{i, l}^{H V A C} t \leq P_{l}^{H V A C \max } \\
H_{i, l}^{H V A C} \leq M v_{i, l}, C_{i, l}^{H V A C} \leq M\left(1-v_{i, l}\right) \\
H_{i, l}^{E B}=H_{i, l}^{D H W}
\end{gathered}
$$

For all $i=0$ to $N_{i}, l=1$ to $N_{l}$

\section{2) Storage operating limits}

Constraint (5) ensures that the BES energy content is within the capacity limit. Constraints (6)-(7) ensure that the charging and discharging rate of BES is within the given range. Constraint (8) is set to make sure that at each location, BES does not charge and discharge at the same time.

$$
\begin{gathered}
B_{l}^{\text {min }} \leq B_{i, l} \leq B_{l}^{\text {max }} \\
P_{l}^{B E S \min } \leq P_{i, l}^{B E S+} \leq P_{l}^{B E S m a x} \\
P_{l}^{B E S \min } \leq P_{i, l}^{B E S-} \leq P_{l}^{B E S m a x} \\
P_{l}^{B E S+} \leq M w_{i, l}, P_{l}^{B E S-} \leq M\left(1-w_{i, l}\right)
\end{gathered}
$$

For all $i=1$ to $N_{i}, l=1$ to $N_{l}$

\section{3) Initialisation}

Equation (9) ensures that the energy level of BES, and building at the initial time step are equal to the last time-step, which guarantees that the results are not distorted.

For all $l=1$ to $N_{l}$

$$
B_{0, l}=B_{N_{i}, l},, T_{0, l}=T_{N_{i}, l}
$$

\section{4) Building thermal comfort limits}

The building temperature at each location is set to be equal to the set temperature whenever the occupant is active.

$$
\begin{array}{r}
O_{i, l} T_{i, l}=O_{i, l} T_{i, l}^{\text {set }} \\
\text { For all } i=1 \text { to } N_{i}, l=1 \text { to } N_{l}
\end{array}
$$

\section{5) BES system equation}

The energy content of BES at each location is determined by the BES energy content and BES charging/discharging power at the previous time-step:

$$
\begin{aligned}
& B_{i+1, l}=B_{i, l}+\left(P_{i, l}^{B E S-}-P_{i, l}^{B E S+} / \varphi_{l}\right) t \\
& \text { For all } i=1 \text { to } N_{i}, l=1 \text { to } N_{l}
\end{aligned}
$$

6) Building system equations

The temperature of each building is defined in (12), which is determined by the building temperature, heat losses to the outdoor environment, space heating/cooling load in the previous time-step, and the metabolic and solar heat gains. Constraint (13) takes into consideration natural occupant cooling behavior (i.e., opening the window and operating the blinds). In (13), $W$ and $S$ are binary parameters. $W$ is 1 in the winter, allowing heat gains to be vented through window opening. $S$ is 1 in the summer, allowing solar heat gains (up to the value of the blind exclusion efficiency $\delta$ ) to be blocked.

$$
\begin{gathered}
T_{i+1, l}=T_{i, l}+\left(H_{i, l}^{H V A C}-C_{i, l}^{H V A C}+\left(1-\pi_{i, l}\right) I n t_{i, l}+\right. \\
\left.\left(1-\beta_{i, l}\right) S o l_{i, l}-\left(T_{i, l}-T_{i}^{o u t}\right) t R_{l}^{b^{-1}}\right) C_{l}^{b^{-1}} \\
0 \leq \pi_{i, l} \leq W, 0 \leq \beta_{i, l} \leq W+S \delta \\
\text { For all } i=1 \text { to } N_{i}, l=1 \text { to } N_{l}
\end{gathered}
$$




\section{B. Energy balance}

\section{1) Resource-location energy balance}

The electricity consumption and generation from the base load, EB, HVAC, PV, and BES are summed up at each location using (14). Constraint (15) ensures that the location does not import and export electricity at the same time.

$$
\begin{aligned}
& E_{i, l}^{-}-E_{i, l}^{+}=\frac{H_{i, l}^{E B}}{\rho_{i, l}^{E B}}+\frac{H_{i, l}^{H V A C}+C_{i, l}^{H V A C}}{\rho_{i, l}^{H V A C}}+P_{i, l}^{B E S-} t- \\
& \quad P_{i, l}^{B E S+} t / \varphi_{l}+E_{i, l}^{l o a d}-E_{i, l}^{\text {solar }} \\
& E_{i, l}^{-} \leq M y_{i, l}, E_{i, l}^{+} \leq M\left(1-y_{i, l}\right), E_{i, l}^{-}, E_{i, l}^{+} \geq 0 \\
& \text { For all } i=1 \text { to } N_{i}, l=1 \text { to } N_{l} \\
& \text { 2) Location-GCP energy balance }
\end{aligned}
$$

Equation (16) aggregates the electricity import and export from each location to GCP level, so as to apply the UoS charges. The electricity import and export are ensured not to happen at the same time using (17).

$$
\begin{gathered}
E_{i, g}^{-}-E_{i, g}^{+}=\sum_{l=1}^{N_{l}} \phi_{g, l}^{G L}\left(E_{i, l}^{-}-E_{i, l}^{+}\right) \\
E_{i, g}^{-} \leq M z_{i, g}, E_{i, g}^{+} \leq M\left(1-z_{i, g}\right), E_{i, g}^{-}, E_{i, g}^{+} \geq 0
\end{gathered}
$$$$
\text { For all } i=1 \text { to } N_{i}, g=1 \text { to } N_{g}
$$

\section{3) GCP energy balance}

The import and export electricity at GCP level are aggregated at VPP level using (18). Only net value is utilized here as the VPP level is only relevant to system level markets where UoS charges are not applicable.

$$
E_{i, v}=\sum_{g=1}^{N_{g}} \phi_{v, g}^{V G}\left(E_{i, g}^{-}-E_{i, g}^{+}\right)
$$

For all $i=1$ to $N_{i}, g=1$ to $N_{g}, v=1$ to $N_{v}$

\section{Objectives}

The objective functions of simulation, based on daily profiles with half-hour resolution, are presented below:

\section{1) A: Energy minimization}

The first objective function aims to minimize the total energy consumption, and is given by:

$$
\begin{aligned}
& O b j_{A}=\operatorname{Min}\left\{\sum_{i=1}^{N_{i}} \sum_{l=1}^{N_{l}}\left(H_{i, l}^{E B}+H_{i, l}^{H V A C}+C_{i, l}^{H V A C}\right)\right\} \\
& \text { For all } i=1 \text { to } N_{i}, l=1 \text { to } N_{l} \\
& \text { 2) B: Cost minimisation }
\end{aligned}
$$

The second option is to minimize the cost to maximize net benefit, which is given by:

$$
\begin{gathered}
\operatorname{Obj}_{B}=\operatorname{Min}\left\{\sum _ { i = 1 } ^ { N _ { i } } \left(\lambda_{i} \sum_{v=1}^{N_{v}} E_{i, v}+\sum_{g=1}^{N_{g}} \lambda_{i, g}^{-} E_{i, g}^{-}+\right.\right. \\
\left.\left.\sum_{l=1}^{N_{l}} \lambda_{i, l}^{-} E_{i, l}^{-}\right)\right\}
\end{gathered}
$$

\section{blind exclusion efficiency is set to 0.47 [14].}

For all $i=1$ to $N_{i}, l=1$ to $N_{l}, g=1$ to $N_{g}, v=1$ to $N_{v}$

3) $C$ : Electricity self-sufficiency

The objective function of electricity self-sufficiency seeks to minimize the import and export electricity at each time step:

$$
\begin{gathered}
O b j_{C}=\operatorname{Min}\left\{\sum_{i=1}^{N_{i}} \sum_{l=1}^{N_{l}}\left(E_{i, l}^{-}+E_{i, l}^{+}\right)\right\} \\
\text {For all } i=1 \text { to } N_{i}, l=1 \text { to } N_{l}
\end{gathered}
$$

\section{CASE STUDY}

The employed model is demonstrated through case studies of a residential and a commercial community in the context of Victoria (VIC), Australia. Different scenarios are created based on various technology options (i.e., PV and BES). Each case is optimized under three objectives, i.e., energy minimization, cost minimization, and electricity self-sufficiency. Moreover, to understand the effect of cost optimization given various price
Based on the assumptions indicated above the network limit is determined according to the maximum energy demand for each community without PV and BES installations. Thus, the network limits are sized to $154.89 \mathrm{kVA}$ and $123.56 \mathrm{kVA}$ for residential and commercial communities respectively.

\section{B. Technology options}

Three technology options are considered in the case study, as shown in Table I. Neither PV nor BES is installed in base case $\alpha$. For $\beta$, a $4.125 \mathrm{~kW} \mathrm{PV}$ is added to each terraced house whilst a $5.5 \mathrm{~kW}$ PV is added to each retail shop, where the PV is sized based on the maximum community export power that can be accommodated by the network limit. For case $\gamma$, a 4.8 $\mathrm{kW}$ PV is added to each terraced house and a $7.5 \mathrm{~kW}$ PV is added to each retail. That will cause a maximum export power which exceeds the network limit by $20 \%$ without any flexibility options. The BES is then sized to enable the maximum community power to remain below an acceptable level.

\begin{tabular}{cllll} 
TABLE I. & \multicolumn{5}{c}{ TECHNOLOGY OPTIONS AND PARAMETERS PER BUILDING } \\
\hline Community & Options & PV capacity & BES capacity & BES power \\
\hline \multirow{2}{*}{ Residential } & $\alpha$ & - & - & - \\
community & $\beta$ & $4.125 \mathrm{~kW}$ & - & - \\
& $\gamma$ & $4.8 \mathrm{~kW}$ & $7 \mathrm{kWh}$ & $5 \mathrm{~kW}$ \\
\hline \multirow{2}{*}{ Commercial } & $\alpha$ & - & - & - \\
community & $\beta$ & $5.5 \mathrm{~kW}$ & - & - \\
& $\gamma$ & $7.5 \mathrm{~kW}$ & $12 \mathrm{kWh}$ & $8.52 \mathrm{~kW}$ \\
\hline
\end{tabular}

signals, five scenarios relating to different energy price

The annual community revenues are the aggregations of the simulation results of eight typical days, which are composed of
summer/shoulder/winter weekday/weekend, a peak summer day with greatest solar insolation, and a peak winter day with the coldest weather without solar insolation. The different

\begin{tabular}{|c|c|c|}
\hline \multirow[b]{2}{*}{ Level } & \multirow[b]{2}{*}{ Component } & Applicability \\
\hline & & Import Export \\
\hline Commercial & Wholesale electricity & \\
\hline \multirow[t]{3}{*}{ GCP } & Distribution UoS (DUoS) fees & \\
\hline & Jurisdictional UoS (JUoS) fees & \\
\hline & Transmission UoS (TUoS) fees & \\
\hline \multirow[t]{2}{*}{ Premises } & Environmental\&social obligation (ESO) & \\
\hline & Goods and sales tax (GST) & \\
\hline
\end{tabular}
studied cases are presented below.

\section{A. Community description and network limit}

insulated terraced houses, while the commercial community contains 30 retail shops. For each dwelling, DHW demand, dwelling thermal characteristics are randomly generated based on UK parameters [11], [12]. Based on observed UK data [13] and occupancy, the building set temperatures are $21^{\circ} \mathrm{C}$ and 20 ${ }^{\circ} \mathrm{C}$ for terraced house and retail respectively. The HVAC is
sized to meet space heating/cooling demands to ensure thermal comfort, whilst the EB is sized to meet DHW demand. The

\section{Energy prices}

A crucial part of the optimization and realistic assessment is the treatment of energy prices. Table II shows the energy price components in the context of VIC.

TABLE II. ELECTRICITY PRICE COMPONENTS

The energy prices are broken down into component parts, each being applied at the appropriate aggregation level (i.e., 
commercial, GCP, and premises) [15]. All components are applicable to import electricity. The communities are paid for export electricity, while the DUoS credit might be received, depending on the specific tariff [16]. Based on the various electricity-related prices components in VIC context, five price signal studies are defined and illustrated in Table III.

\begin{tabular}{|c|c|}
\hline TABLE II & $\begin{array}{l}\text { PRICE SIGNALSTUDYS } \\
\text { Descrintion }\end{array}$ \\
\hline 1 & Retail prices \\
\hline 2 & Wholesale electricity prices \\
\hline 3 & TUoS \\
\hline 4 & DUoS and JUoS \\
\hline 5 & All price signals \\
\hline
\end{tabular}

In each study, the price signal relating to different electricity cost components is set to be visible. In option 1, the retail prices refer to the flat prices for electricity across the year, i.e., 0.25 $\$ / \mathrm{kWh}$ for import and $0.05 \$ / \mathrm{kWh}$ for export [16]. The energy price components for a peak summer day are shown in Fig 1.

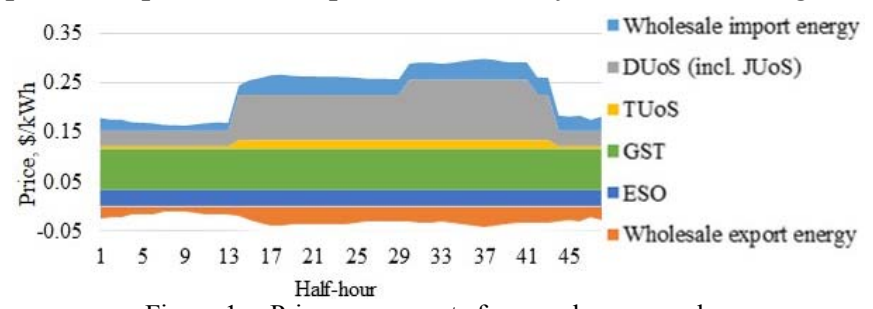

\section{Objectives}

The proposed communities with different technologies and various prices components are modelled under three different objectives, and are listed in Table IV.

\begin{tabular}{|c|c|}
\hline Objectives & Description \\
\hline $\bar{A}$ & Energy minimization \\
\hline B & Cost minimization \\
\hline $\mathrm{C}$ & Electricity self-sufficiency \\
\hline
\end{tabular}

\section{RESULTS}

In this section, the community behavior of different cases is presented first. Subsequently, the community cash flows and discounted payback period are demonstrated.

\section{A. Community behavior}

Fig. 2 illustrates the community behavior of residential and commercial communities on a peak summer day. It can be seen that the operational profiles for the same technology option under different objectives are distinctive.

For both communities, under cost minimization objective, the operation of BES changes significantly when shift from applying retail price signal $(\mathrm{B} / \gamma / 1)$ to all price signals $(\mathrm{B} / \gamma / 5)$, as so to avoid higher priced imports and to increase higher priced export. However, both cases stress the network during the daytime by exporting surplus PV generation. That may be acceptable, as the community can operate above their nominal capacities for a limited duration. The network constraint has been significantly ameliorated under electricity self-efficiency objective. In that case, HVAC demand is notably increased during the day to soak the PV generation. As a consequence, more electricity is consumed compared to cost minimization solutions, which leads to less economic benefit with regards to operational revenue.

\section{B. Cost}

Fig. 3 demonstrates the changes in operational revenue of residential community in different cases comparing to the base case $\mathrm{A} / \alpha$, and the discounted payback periods of PV and BES investment. Cost minimization objective brings more net flow benefits compared to others. Although less electricity is consumed under energy minimization, there is no optimization in the operation of the flexible devices, which leads to less economic benefits. The electricity self-sufficiency objective tends to consume more electricity to soak PV generation to minimize net export/import, which leads to a conclusion that electricity self-sufficiency is not the best economic solution.

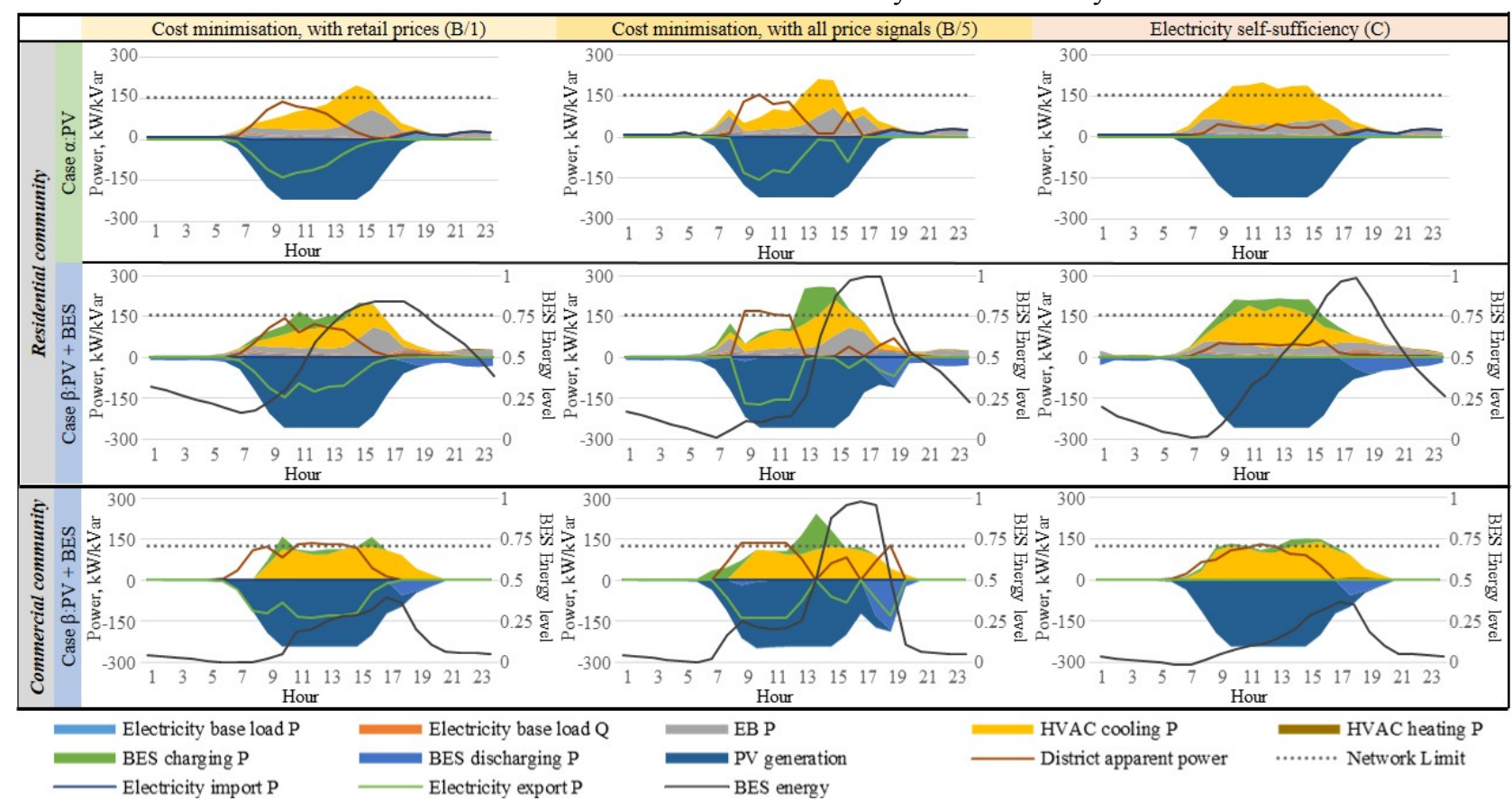

Figure 2. Community behavior, by case, peak summer day. Top: residential community behavior; bottom: commercial community behavior 
The payback period is calculated based on today's PV and BES prices [17] and a discount rate of $4.2 \%$ [18]. Although both $\beta$ and $\gamma$ can bring great increases in revenue, the discounted payback period of case $\gamma$ is much longer than case $\beta$. For instance, the payback period is 9 years for case $B / \gamma$, whilst is 3.4 years for case $\mathrm{B} / \beta$. This could for example hint at the potential need for support from the Distribution Network Operator (DNO) towards BES investment costs, given the avoidance in network reinforcement which they benefit from.

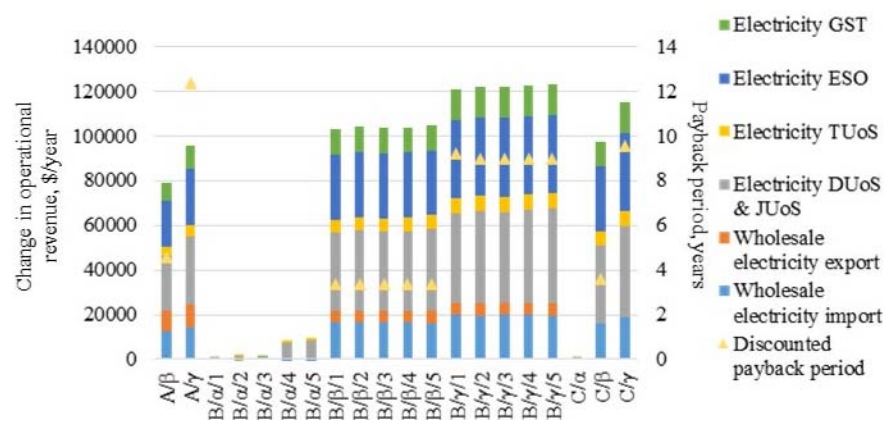

Figure 3. Changes in operational revenue and payback period for communities, compare to base case $\mathrm{A} / \alpha$.

Fig. 4 illustrates the effect of the price signals on the residential community operation revenue changes of PV and BES case $(\gamma)$. It can be seen that among all the savings, DUoS\&JUoS fees bring the most significant benefit to the net flow by reducing the costs (to the community) of importing electricity ${ }^{1}$, due to its most remarkable differential. Meanwhile, except ESO\&GST fees, all price components share a similar trade, i.e., the period of high wholesale electricity prices correspond to high TUoS and DUoS\&JUoS fees. Thus, optimization on one relevant price signal will lead to benefits gained from others.

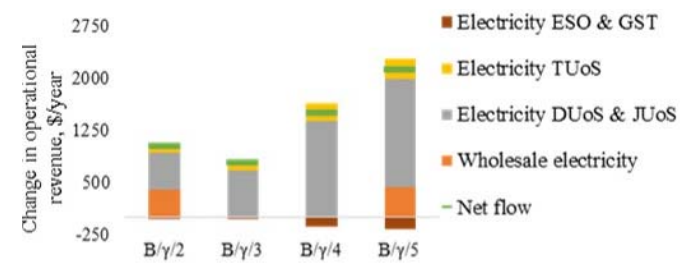

Figure 4. Changes in operation revenue for residential community compared to $\mathrm{B} / \gamma / 1$, by price signal cases

\section{CONCLUSION}

This paper has demonstrated a community optimization model which considers multi-energy demand and is able to model different energy resources and flexible devices such as $\mathrm{PV}, \mathrm{EB}, \mathrm{HVAC}$, and BES. Using a storage sizing approach for aims of energy independence and network reinforcement avoidance, two communities with various technology options are modelled under different objectives, while applying five different price signals. The case study is used to demonstrate how those different options can ameliorate/stress the network constraints as well as the cost benefits that can be gained. It can be concluded that although the network constraints can be substantially ameliorated under electricity self-sufficiency objective, it is not the best economic option compared to cost minimization solutions. Under cost minimization objective, applying price signals can reduce the operation costs by optimizing the operation of flexible energy devices. However, the network constraints are stressed compared to using flat retail prices. Meanwhile, although installing PV and BES can bring revenue to the community, the payback period of the investment costs of installing both PV and BES are comparably higher than the PV installation case, which makes this option less attractive without payments from DNO.

Future work will demonstrate the benefits of different network aggregations and commercial options using CBA, network constraints and energy independence metrics.

\section{REFERENCES}

[1] Bureau of Resources and Energy Economics, "Australian Energy Technology Assessment," 2012.

[2] A. Navarro-Espinosa and L. F. Ochoa, "Probabilistic Impact Assessment of Low Carbon Technologies in LV Distribution Systems," IEEE Trans. Power Syst., pp. 1-12, 2015.

[3] A. Navarro-Espinosa and P. Mancarella, "Probabilistic Modeling and Assessment of the Impact of Electric Heat Pumps on Low Voltage Distribution Networks," Appl. Energy, vol. 127, no. 15 August 2014, pp. 249-266.

[4] N. Good, K. A. Ellis, and P. Mancarella, "Demand Response and the Smart Grid: Review, Analysis and Classification of Socio-TechnoEconomic Barriers and Enablers," Renew. Sustain. Energy Rev., vol. Submitted.

[5] R. Khalilpour and A. Vassallo, "Leaving the grid: An ambition or a real choice?," Energy Policy, vol. 82, no. 1, pp. 207-221, 2015.

[6] N. Good, E. Karangelos, A. Navarro-Espinosa, and P. Mancarella, "Optimization under Uncertainty of Thermal Storage-Based Flexible Demand Response with Quantification of Residential Users' Discomfort," IEEE Trans. Smart Grid, vol. 6, no. 5, pp. 2333-2342, 2015.

[7] N. Good, P. Mancarella, and K. Lintern, "Techno-economic Assessment of Flexibility Options in Community Energy Systems," in PowerTech, 2017.

[8] E. A. Martínez Ceseña, N. Good, and P. Mancarella, "Electrical Network Capacity Support from Demand Side Response: Techno-economic Assessment of Potential Business Cases for Small Commercial and Residential end-users," Energy Policy, vol. 82, no. 1, pp. 222-232, Jul. 2015.

[9] N. Good and P. Mancarella, "Modelling and assessment of business cases for smart multi-energy districts," 19th Power Syst. Comput. Conf. PSCC 2016, 2016.

[10] N. Good, E. A. Martínez-Ceseña, L. Zhang, and P. Mancarella, "TechnoEconomic and Business Case Assessment of Low Carbon Technologies in Distributed Multi-Energy Systems," Appl. Energy, vol. 167, pp. 158$172,2016$.

[11] I. Richardson, M. Thomson, D. Infield, and C. Clifford, "Domestic Electricity Use: A High-resolution Energy Demand Model," Energy Build., vol. 42, no. 10, pp. 1878-1887, Oct. 2010.

[12] N. Good, L. Zhang, A. Navarro-Espinosa, and P. Mancarella, "High Resolution Modelling of Multi-energy Domestic Demand Profiles," Appl. Energy, vol. 137, pp. 193-210, Jan. 2015.

[13] M. Shipworth, S. Firth, M. Gentry, A. Wright, D. Shipworth, and K. Lomas, "Central heating thermostat settings and timing: building demographics," Build. Res. Inf., vol. 38, no. 1, pp. 50-69, Jan. 2010.

[14] Chartered Institute of Building Services Engineers, Environmental Design: CIBSE guide A, 7, illustr ed. CIBSE, 2006.

[15] L. Hoch, R. Harris, and T. White, "Causes of residential electricity bill changes in Victoria, 1995 to 2013," 2014.

[16] AusNet Services, "Electricity Distribution: Annual Tariff Proposal 2016," 2016.

[17] "Australia's Solar Power System Installation Brokers - Solar Choice." [Online]. Available: http://www.solarchoice.net.au/. [Accessed: 16-Feb2017].

[18] AEMO, "Australian Energy Market Operator 2016 Annual Report," 2016.

\footnotetext{
Note that these savings may not persist. If, as a result of community optimisation, the DNO cannot recover its costs UoS fee price structures and levels will change, possibly reducing the cost savings available to the community.
} 